\title{
Special Issue on the Economics of Local Food Markets
}

\section{David R. Just and Garrick Blalock}

In October 2010, Walmart announced that it would be doubling its offerings of locally grown produce within its extensive network of retail stores. Other more traditional grocery chains, such as Safeway, Kroger, and Wegmans, have followed suit, touting their own local offerings. In each case, these retailers claim that local food sources may reduce costs, increase the quality and freshness of produce, and reduce the carbon emissions due to transportation. However, local foods (and produce in particular) may be available only within a narrow season of the year. These changes come about ostensibly in response to pressure from consumer groups concerned with issues of environmental sustainability. It is unclear how this reshaping of the food supply chain will impact farmers, consumers, and retailers.

The first four articles within this issue were originally presented as part of the Northeastern Agricultural and Resource Economics Association's workshop on the Economics of Local Food Markets, held in Atlantic City, New Jersey, in June 2010. The goal of this workshop was to highlight current research and bring together researchers, extension educators, private sector participants, and policymakers to exchange ideas and develop a common set of priority research and education needs for local food systems. The workshop included both prominent invited speakers (the paper of invited speaker Carolyn Dimitri appeared in the October 2010 issue) and several contributed papers. These four papers represent a cross section of the views presented.

David R. Just is Associate Professor and Director of the Cornell Center for Behavioral Economics in Child Nutrition Programs, and Garrick Blalock is Associate Professor in the Dyson School of Applied Economics and Management, both at Cornell University, in Ithaca, New York.
Kathryn Onken, John Bernard, and John Pesek, Jr., use experimental methods to examine the impact of state programs to market organic, natural, and locally grown foods on consumer valuation. Each of the five states included in their analysis have ongoing promotional programs (Jersey Fresh, PA Preferred, Grown Fresh with Care in Delaware, Virginia's Finest, Maryland's Best). The authors find substantial consumer preference for local foods, though no detectable preference for organic over other natural foods. The strength of preference for local foods was much higher among farmers market patrons than those of retail grocery stores.

William Nganje, Renée Hughner, and Nicholas Lee use survey methods to address consumer willingness to pay for locally grown or state-branded produce, focusing on issues of food safety and traceability. They find a substantial premium for locally grown foods that is associated with consumer preference for safety. Alternatively, traceability does not appear to be as important to the consumer.

Ferdinand Wirth, John Stanton, and James Wiley conduct a conjoint analysis experiment to quantify the relative importance of observable quality attributes versus credence attributes such as organic or locally grown foods. Their analysis shows that observed quality attributes appear to be much more important than credence attributes in the context of consumer preferences. Thus, it may be that better-looking produce will trump locally grown or other credence attributes in a competitive consumer market.

Finally, Hiroki Uematsu and Ashok Mishra examine the impact of direct marketing of farm products to consumers on farm business income. Using a large national survey and quantile regres- 
sion techniques, they find that direct marketing strategies have little impact on farmer income, and that the use of farmers markets is negatively associated with income. They suggest that direct marketing to consumers may be more of a risk management tool than a tool for increasing profits or revenue. Moreover, lower average profits may be due to the added labor requirements of direct marketing strategies. Both of their results call into question the true sustainability of local food systems from the standpoint of producers.

We thank the participants in the workshop, those who helped organize it, and especially the U.S. Department of Agriculture's Economics Research Service, the Farm Foundation, and the Northeast Regional Center for Rural Development for funding the successful workshop. 